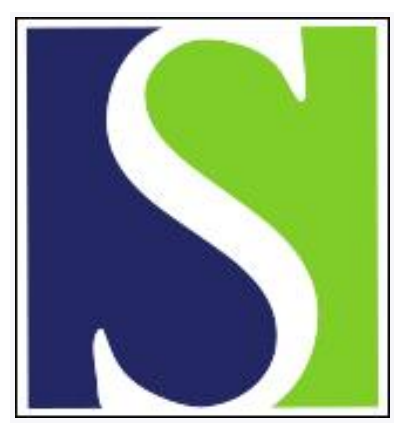

Scand J Work Environ Health 1984;10(5):305-309

https://doi.org/10.5271/sjweh.2324

Issue date: Oct 1984

A filter method for the active and passive monitoring of sulfur dioxide in workplace air.

by Hallberg BO, Rudling J, Hultman A, Hultengren M

This article in PubMed: www.ncbi.nlm.nih.gov/pubmed/6523095

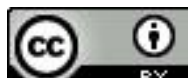




\title{
A filter method for the active and passive monitoring of sulfur dioxide in workplace air
}

\author{
by Bengt-Olov Hallberg, BSc, Jan Rudling, BSc, Annika Hultman, BSc, May Hultengren ${ }^{1}$
}

\begin{abstract}
HALLBERG B-O, RUDLING J, HULTMAN A, HULTENGREN M. A filter method for the active and passive monitoring of sulfur dioxide in workplace air. Scand J Work Environ Health 10 (1984) 305-309. A method where sulfur dioxide is collected on impregnated filters (glycerol/potassium hydroxide solution) is described. Sampling can be done either with a pump or by the use of two different passive monitors available on the market. Analysis is made by ion chromatography. The methods have been evaluated and compared with a colorimetric air monitoring badge system (ProTek). Laboratory tests show that the accuracy of the filter methods is acceptable and that samples can be stored. Water vapor does not intefere, but hydrogen sulfide causes a minor decrease in recovery. ProTek has high accuracy but storage tends to decrease the recovery. Field tests in a steel rolling mill and a sulfite pulp mill showed a fairly good correspondence between the methods.
\end{abstract}

Key terms: ion chromatography, passive monitor, sampling.

Sulfur dioxide $\left(\mathrm{SO}_{2}\right)$ is a common pollutant in industrial air. It is formed in the combustion of fossile fuels but can also be encountered in various industrial processes such as metalcasting and the manufacturing of sulfite pulp and sulfuric acid. Sulfur dioxide is a known irritant to respiratory organs. In Sweden the standard for occupational exposure is $5 \mathrm{mg} / \mathrm{m}^{3}$ (time-weighted average limit) and $13 \mathrm{mg} / \mathrm{m}^{3}$ (limit for a 15 -min period).

The technique most widely used for sampling sulfur dioxide is collection with midget impingers with dilute hydrogen peroxide $(10,13,14)$ or tetrachloromercurate (8) as the absorbing solution. For the former, photometric titration $(10,14)$ or ion chromatography (13) has been used for the analysis, and, for the latter, analysis by colorimetry is common (8). Impinger methods are not suitable for exposure measurements, and therefore other sampling procedures have been developed. Volberg \& Sharikova (19) ased coated glass beads, Smith et al (15) employed impregnated charcoal, and the National Institute for Occupational Safety and Health (NIOSH) (11) recommends impregnated filters. Sulfur dioxide can also be collected on molecular sieve $5 \mathrm{~A}$ followed by heat desorption and analysis by mass spectrometry (9) or gas chromatography with a flame photometric detector (1). With the use of a triethanolaminecoated molecular sieve and subsequent analysis with

\footnotetext{
1 National Board of Occupational Safety and Health, Solna, Sweden.
}

Reprint requests to: Mr J Rudling, National Board of Occupational Safety and Health, S-171 84 Solna, Sweden. ion chromatography, the simultaneous determination of nitrogen dioxide and sulfur dioxide is possible (18).

Passive monitoring based on controlled diffusion is an attractive alternative for sampling since no pumps are required. In a passive monitor, ProTek ${ }^{\mathrm{TM}}$ (manufactured by DuPont), tetrachloromercurate is used as an absorbing solution, and the analysis is made by colorimetry with the aid of analytical reagents stored as ampuls in the monitor. The method has been documented (6) and evaluated against the traditional impinger methods (5). Recently a tubular sampler with the same type of absorbing solution and analytical reagents as ProTek has been described (2).

The purpose of the present work was to develop a method that could be used for the passive monitoring of sulfur dioxide. For short-term samples it should be possible to use the same collection media in conjunction with a pump in order to increase the sampling rate. The choice fell on impregnated filters that are easy to prepare and use with the passive monitors available on the market. In a prestudy several filter materials and impregnating solutions were tried, and it was found that glass fiber filters impregnated with a potassium hydroxide/glycerol solution yielded good results. In order to make the analysis more specific than the colorimetric methods commonly used, ion chromatography was used to determine the sample as sulfate ion after oxidation with hydrogen peroxide. For the laboratory and field evaluations we considered a comparison with another method (based on other principles for sampling and analysis) valuable, and therefore the ProTek monitor was also included in the study. 


\section{Materials and methods}

\section{Sampling}

Before use in an ordinary filter casette, glass fiber filters (Whatman GF/A, $37 \mathrm{~mm}$ ) were dipped in an aqueous solution containing potassium hydroxide ( 80 $\mathrm{g} / \mathrm{l})$ and glycerol $(40 \mathrm{ml} / \mathrm{l})$, allowed to drip off, and dried at $60{ }^{\circ} \mathrm{C}$ for $1 \mathrm{~h}$. Treated filters should be stored dry prior to usage. For the sampling the filter was loaded in a casette and connected to a pump with a flow rate of $1 \mathrm{l} / \mathrm{min}$. If a long storage period is needed after the sampling, refrigeration is recommended.

For passive sampling two types of monitors have been used, the Gasbadge ${ }^{\mathrm{TM}}$ and the $3 \mathrm{M}$ (Minnesota Mining and Manufacturing $\mathrm{Co}$ ) organic vapor monitor 3500 . The Gasbadge monitor has been described in detail in another paper (17). The organic vapor monitor consists of a nylon disk about $4.5 \mathrm{~cm}$ in diameter. The adsorbent is separated from an outer porous membrane by spacers. Filters $(38 \times 44 \mathrm{~mm}$ for the Gasbadge and $30 \mathrm{~mm}$ in diameter for the organic vapor monitor) are cut from a sheet (Whatman GF/A $460 \times 570 \mathrm{~mm}$ ) and prepared as described in the preceding paragraph. The sampling rate for a passive monitor is based upon Fick's first law of diffusion, and, if we assume that the sorbent acts as a perfect sink, the sampling rate, $\mathrm{f}\left(\mathrm{cm}^{3} / \mathrm{min}\right)$, is given by (7):

$$
\mathrm{f}=(\mathrm{D} \times \mathrm{A} \times 60) / \mathrm{L},
$$

where $\mathrm{D}=$ the diffusion coefficient $\left(\mathrm{cm}^{2} / \mathrm{s}\right)$, $\mathrm{L}=$ the diffusive path $(\mathrm{cm})$, and $\mathrm{A}=$ the cross-section area of the sampler $\left(\mathrm{cm}^{2}\right)$.

With a diffusion coefficient of 0.1220 (4) and a A : L ratio of 7.0 for the Gasbadge and 5.9 for the organic vapor monitor (measured), the calculated sampling rate is 51.2 and $43.2 \mathrm{~cm}^{3} / \mathrm{min}$, respectively. For practical reasons, the sampling rate is usually determined from exposure of the samplers to known concentrations of sulfur dioxide in air. A good correspondence between the calculated and experimentally determined sampling rate is an indication that the method works as expected.

The ProTek samplers (lot number C-20-183 \& C-20-185) are also based upon diffusion. Gas molecules enter the sampler through a diffusor and a po-

Table 1. Ion chromatographic conditions.

\begin{tabular}{ll}
\hline Parameter & Material used/setting \\
\hline Columns & $4 \times 50 \mathrm{~mm}$ Dionex anion concentrator \\
& $4 \times 250 \mathrm{~mm}$ Dionex anion separator \\
& $9 \times 100 \mathrm{~mm}$ Dionex anion suppressor \\
Flow & $115 \mathrm{ml} / \mathrm{h}$ \\
Eluent & $0.0030-\mathrm{mol} / \mathrm{l}$ sodium bicarbonate \\
Sample volume & $0.0024-\mathrm{mol} / \mathrm{l}$ sodium carbonate \\
Detector & $100 \mu \mathrm{l}$ \\
Sensitivity & Conductivity \\
\hline
\end{tabular}

rous tape into an absorbing solution containing tetrachloromercurate. A detailed description of the sampler has been given by Kring et al (6).

\section{Analysis}

After the sampling, the filters are leached in an aqueous solution $(10-50 \mathrm{ml})$ containing sodium carbonate $(0.25 \mathrm{~g} / 1)$, sodium bicarbonate $(0.25 \mathrm{~g} / \mathrm{l})$, and $30 \%$ hydrogen peroxide $(4 \mathrm{ml} / \mathrm{l})$, shaken gently for $30 \mathrm{~min}$, and after filtration of an aliquot analysis is made by ion chromatography. A Dionex 14 ion chromatograph equipped with a Hewlett-Packard 3388 integrator is used with the analytical conditions given in table 1. For most analyses two concentrator columns connected in series was sufficient to separate the sulfate ions from other ionic species. This system decreases the analysis time to about $10 \mathrm{~min}$. If the coefficient of variation (CV) for the analysis is to be $\leq 10 \%$, the smallest concentration to be quantified is about $20 \mu \mathrm{mol} / 1$. This limit corresponds to about $1.0 \mathrm{mg} / \mathrm{m}^{3}$ if a $15-\mathrm{l}$ air sample is taken with a pump and to about $0.8 \mathrm{mg} / \mathrm{m}^{3}$ if an $8-\mathrm{h}$ sample is taken with a passive monitor.

For ProTek the analysis involves pressing the reagent ampuls that are stored in the sampler and making the reagents mix with the absorbing solution. The intensity of the color formed is then determined after the sampler is inserted into a specially designed photometer (PT-3). The result is given directly in parts per million times hours. Calibration is made by the use of two calibration cards. Most analyses (all field samples) were made with a spectrophotometric method (10- or 40-mm cuvettes) supplied by DuPont. The range of the method is $10-100 \mathrm{ppm} \times \mathrm{h}$ $\left(25-250 \mathrm{mg} / \mathrm{m}^{3} \times \mathrm{h}\right)$ if the PT-3 is used. If the spectrophotometric method is used with a $40-\mathrm{mm}$ cuvette, the lower limit is extended to about $2 \mathrm{ppm} \times \mathrm{h}$ $\left(5 \mathrm{mg} / \mathrm{m}^{3} \times \mathrm{h}\right.$ ).

\section{Generation of test atmospheres}

Sulfur dioxide was generated through the dilution of concentrated gas from a cylinder containing $0.30 \%$ (by volume) sulfur dioxide (in nitrogen) in previously described dynamic systems (12). The certified cylinder content was controlled by the passing of a known volume of gas through a fritted bubbler bottle containing iodine $(0.01 \mathrm{~mol} / \mathrm{l})$ with starch as the indicator. An excellent agreement with the certificate supplied by the manufacturer (Alfax) was obtained.

As an additional control of the test atmosphere, a set of six impinger samples containing $15 \mathrm{ml}$ of absorbing solution ( $40 \mathrm{ml}$ of $30 \%$ hydrogen peroxide is diluted to 11 with distilled water and acidified to $\mathrm{pH}$ 4.5) were taken with each run and analyzed with ion chromatography. The average of these samples did not deviate more than $\pm 5 \%$ from the calculated value in any of the runs. 
For the generation of humidity, the air stream was passed through fritted bubblers with distilled water. The relative humidity was controlled with a humidity meter (Vaisala humicap). As a standard condition $10-15 \%$ relative humidity was used. The air velocity over the passive monitors to be tested was $0.24 \mathrm{~m} / \mathrm{s}$ (calculated from the geometry of the test chamber). Periodic checks with a hot-wire anemometer showed values close to this level.

\section{Field tests}

The field tests were carried out in two different environments, a steel rolling mill where sulfur dioxide was emitted from oil-fired furnaces and a sulfite pulp mill where sulfur dioxide originated from leaks in the process equipment. In every plant six stationary and six personal sampling sites were selected (sampling time $8 \mathrm{~h}$ ). The stationary samples were taken as duplicates, and the sampling devices were mounted on a rack (with a maximum distance of $40 \mathrm{~cm}$ between the samplers) with randomized positions of the samplers. The personal samples were taken with samplers affixed as close as possible to each other. In the steel rolling mill prefilters were used for the filter samples taken with a pump.

\section{Results and discussion}

\section{Laboratory tests}

The collection efficiency for the filter samples taken with a pump was determined by the following process: two filters were connected in series, sulfur dioxide $\left(25 \mathrm{mg} / \mathrm{m}^{3}\right)$ was sampled for $1-8 \mathrm{~h}$, and the proportion collected on the first filter (collection efficiency) was determined. A collection efficiency of $>98 \%$ was achieved for all the samples $(\mathrm{N}=8)$. Thus it was possible to sample $25-\mathrm{mg} / \mathrm{m}^{3}$ sulfur dioxide for a whole workday. Since the sampling rate of the passive monitors is much smaller than $1 \mathrm{l} / \mathrm{min}$, the capacity of the passive monitors should exceed $200 \mathrm{mg} / \mathrm{m}^{3} \times \mathrm{h}$.

The effect of humidity on the sampling was determined from a test atmosphere containing $10-\mathrm{mg} / \mathrm{m}^{3}$ sulfur dioxide and $80 \%$ relative humidity and six samples collected with a pump for $6 \mathrm{~h}$. An average recovery of $100 \%$ was achieved. Interference from hydrogen sulfide $\left(\mathrm{H}_{2} \mathrm{~S}\right)$ was tested by sampling $5-\mathrm{mg} / \mathrm{m}^{3}$ sulfur dioxide and $20-\mathrm{mg} / \mathrm{m}^{3}$ hydrogen sulfide for $2 \mathrm{~h}$. The average recovery then decreased to $80 \%$. A possible explanation is that some sulfur dioxide was reduced to elementary sulfur either in the gas phase or on the filters.

If aerosols containing sulfate or sulfite are present in the air, they would be recorded as sulfur dioxide when collected on a filter. To eliminate this problem, prefilters (Millipore AAWP) can be used. Tests showed that only insignificant amounts of sulfur dioxide were collected on the prefilter.

Storage stability tests (refrigerator) for six samples with various amounts of sulfur dioxide collected on filters showed no decrease in recovery for three weeks. For ProTek the recovery for six samples stored for four weeks was $84 \%$. The manufacturer claims that samples can be stored at least three weeks. The results indicated that a prolonged storage period should be avoided.

The sampling rate of the passive monitors was determined in three runs during which the samplers were exposed to sulfur dioxide concentrations of 2.5 , 5 , and $10 \mathrm{mg} / \mathrm{m}^{3}$ for $8 \mathrm{~h}$. Five samplers were exposed in each run. From the recovered amounts and with the knowledge of the generated concentrations, the sampling rate was found to be $50.2 \mathrm{~cm}^{3} / \mathrm{min}$ for the Gasbadge and $41.9 \mathrm{~cm}^{3} / \mathrm{min}$ for the organic vapor monitor. These values correspond well with the calculated sampling rates.

The accuracy and precision of the methods was determined from samplers (totally $12-18$ samplers for each method) exposed to different concentrations of sulfur dioxide. The results are shown in table 2 . Some additional tests for short-term samples collected on filters with a pump were also carried out (table 3). For evaluation we have used the NIOSH criterion, which means that we should be able with $95 \%$ confidence to state that a single result is within $\pm 25 \%$ of the true value. This criterion can be expressed as "overall system accuracy (OSA)" (6) according to:

$$
\text { OSA }=|\bar{x}-100|+2 \times \overline{C V} \leq 25 \% \text {, }
$$

Table 2. Recovery and precision for the filter methods and ProTek.

\begin{tabular}{|c|c|c|c|c|c|c|c|c|}
\hline \multirow{2}{*}{$\begin{array}{l}\text { Sulfur } \\
\text { dioxide } \\
\left(\mathrm{mg} / \mathrm{m}^{3}\right)\end{array}$} & \multicolumn{2}{|c|}{ Filter and pump } & \multicolumn{2}{|c|}{$\begin{array}{l}\text { Filter in Gasbadge } \\
\text { monitor }\end{array}$} & \multicolumn{2}{|c|}{$\begin{array}{c}\text { Filter in organic vapor } \\
\text { monitor }\end{array}$} & \multicolumn{2}{|c|}{ ProTek a } \\
\hline & $\begin{array}{c}\text { Recovery } \\
(\%)\end{array}$ & $\begin{array}{c}\text { Coefficient } \\
\text { of variation } \\
(\%)\end{array}$ & $\begin{array}{l}\text { Recovery } \\
(\%)\end{array}$ & $\begin{array}{c}\text { Coefficient } \\
\text { of variation } \\
(\%)\end{array}$ & $\begin{array}{l}\text { Recovery } \\
(\%)\end{array}$ & $\begin{array}{c}\text { Coefficient } \\
\text { of variation } \\
(\%)\end{array}$ & $\begin{array}{l}\text { Recovery } \\
(\%)\end{array}$ & $\begin{array}{c}\text { Coefficient } \\
\text { of variation } \\
(\%)\end{array}$ \\
\hline $\begin{array}{c}2.5 \\
5 \\
10 \\
\end{array}$ & $\begin{array}{r}\ddot{95} \\
103\end{array}$ & $\begin{array}{l}6.4 \\
2.1 \\
\end{array}$ & $\begin{array}{r}102 \\
99 \\
91 \\
\end{array}$ & $\begin{array}{c}12 \\
10 \\
3.8 \\
\end{array}$ & $\begin{array}{r}108 \\
91 \\
95 \\
\end{array}$ & $\begin{array}{l}5.4 \\
9.1 \\
7.4 \\
\end{array}$ & $\begin{array}{l}96 \\
97 \\
99 \\
\end{array}$ & $\begin{array}{c}10 \\
3.5 \\
5.1\end{array}$ \\
\hline Average $^{b}$ & 99 & 4.8 & 97 & 9.3 & 98 & 7.4 & 97 & 6.8 \\
\hline
\end{tabular}

a Analyzed with the spectrophotometric method - with the PT-3, the average recovery $=100 \%$ and the pooled coefficient of variation $=10 \%$.

b Average denotes average recovery in percent and pooled coefficient of variation in percent. 
Table 3. Accuracy and precision for short-term samples $(\mathrm{N}=5)$ taken with a filter and pump.

\begin{tabular}{lccc}
\hline $\begin{array}{l}\text { Sampling } \\
\text { time } \\
(\mathrm{min})\end{array}$ & $\begin{array}{c}\text { Sulfur } \\
\text { dioxide } \\
\left(\mathrm{mg} / \mathrm{m}^{3}\right)\end{array}$ & $\begin{array}{c}\text { Recovery } \\
(\%)\end{array}$ & $\begin{array}{c}\text { Coefficient } \\
\text { of variation }^{\mathrm{b}} \\
(\%)\end{array}$ \\
\hline 15 & 5 & 99 & 3.1 \\
$5^{\mathrm{a}}$ & 1.1 & 90 & 5.5 \\
\hline
\end{tabular}

a Sampling rate $2.0 \mathrm{l} / \mathrm{min}$.

b Average recovery $=95 \%$, pooled coefficient of variation $=4.5 \%$.

Table 4. Field samples from a sulfite pulp mill - Sample sites $\mathrm{S} 1, \mathrm{~S} 2$, and $\mathrm{P} 1$ from the acid house; S3, S4, and P2 from the bottom level of the sulfite boilers; and S5, S6, and P3 from the top level of the sulfite boilers. [S = stationary samples (average of duplicates), $\mathrm{P}=$ personal samples]

\begin{tabular}{lcccc}
\hline & \multicolumn{4}{c}{ Sulfur dioxide $\left(\mathrm{mg} / \mathrm{m}^{3}\right)$} \\
\cline { 2 - 5 } $\begin{array}{l}\text { Sample } \\
\text { site }\end{array}$ & $\begin{array}{c}\text { Filter } \\
\text { and } \\
\text { pump }\end{array}$ & $\begin{array}{c}\text { Filter in } \\
\text { Gasbadge } \\
\text { monitor }\end{array}$ & $\begin{array}{c}\text { Filter in } \\
\text { organic } \\
\text { vapor monitor }\end{array}$ & ProTek \\
\hline S1 & 3.8 & 5.1 & 3.9 & 2.7 \\
S2 & 3.1 & 3.7 & 3.0 & 2.2 \\
S3 & 6.0 & 7.4 & 6.1 & 5.2 \\
S4 & 3.3 & 3.9 & 4.1 & 2.7 \\
S5 & 32 & 31 & 31 & 24 \\
S6 & 15 & 20 & 18 & 15 \\
P1 & 2.5 & 3.1 & 2.8 & 1.9 \\
P2 & 2.0 & 2.0 & 2.8 & 1.6 \\
P3 & 8.3 & 11 & 8.8 & 8.5 \\
\hline
\end{tabular}

Table 5. Field samples, steel rolling mill - Sample sites $S 1$ and S2 from above the roller bed, S3 and S6 from the top of the furnace, $\$ 4$ from a location at the furnace door, $\$ 5$ from the same level as the traverse crane, and P1 from around the furnaces. [S = stationary samples (average of duplicates), $\mathrm{P}=$ personal samples]

\begin{tabular}{lcccc}
\hline Sample & \multicolumn{4}{c}{ Sulfur dioxide $\left(\mathrm{mg} / \mathrm{m}^{3}\right)$} \\
\cline { 2 - 5 } site & $\begin{array}{c}\text { Filter } \\
\text { and } \\
\text { pump }\end{array}$ & $\begin{array}{c}\text { Filter in } \\
\text { Gasbadge } \\
\text { monitor }\end{array}$ & $\begin{array}{c}\text { Filter in } \\
\text { organic } \\
\text { vapor monitor }\end{array}$ & ProTek \\
\hline S1 & 1.1 & 1.0 & 1.2 & 1.3 \\
S2 & 2.5 & 2.6 & 2.7 & 3.5 \\
S3 & 1.3 & 1.7 & 1.8 & 0.80 \\
S4 & 0.94 & 1.0 & 1.1 & 0.80 \\
S5 & 4.3 & 3.2 & 4.1 & 4.5 \\
S6 & 3.0 & 3.3 & 2.9 & 2.9 \\
P1 & 1.1 & 0.90 & 0.96 & $<0.8$ \\
\hline
\end{tabular}

where $\overline{\mathrm{x}}=$ average recovery in percent and $\overline{\mathrm{CV}}=$ pooled coefficient of variation in percent. The pooled results from table 2 show that all the methods complied with the criterion, even for the short-term samples.

\section{Field tests}

The results of the field tests are shown in tables 4 and 5. Sampling sites with an average result below 0.8 $\mathrm{mg} / \mathrm{m}^{3}$ have been omitted.

Since the standard deviation for an air sampling method is usually proportional to the mean (constant
CV), we have used a logarithmic transformation (16) of the data (after multiplying by 100) in order to evaluate the results. To test the hypothesis that there are no differences between the means (transformed values) of the methods, a two-sided analysis of variance (3) was performed for the stationary samples from each plant. This procedure was used in order to block out the systematic difference between the sampling sites. Because the number of samples above $0.8 \mathrm{mg} / \mathrm{m}^{3}$ was small, no statistical analysis was performed for the personal sampling sites.

The statistical analysis showed that in the steel rolling mill there was no significant difference between the methods at the $5 \%$ level. In the pulp mill a significant difference $(p<0.01)$ was found. As can be seen from table 4 , the filter samples taken with a pump and the organic vapor monitor corresponded well. The value obtained with the Gasbadge monitor was about $15 \%$ higher and that of the ProTek about $20 \%$ lower than the average for the first-mentioned methods. There are three possible explanations. First, the sampling rate for the Gasbadge monitor could have been affected by the air velocity over the face of the sampler since, as shown in an earlier paper (12), an increase in air velocity increases the sampling rate. Second, the ProTek samplers were stored almost two weeks before the analysis, and, as shown in the laboratory tests, storage tends to decrease recovery. Third, there could have been interfering compounds in the air that affected the filter or ProTek method.

Despite these shortcomings, our interpretation of the field tests is that a fairly good correspondence between the tested methods has been established.

The CV for the tested methods was calculated from the duplicates of the stationary samples from both plants. The calculation was made from the transformed values and transformed back as described by Snedecor \& Cochran (16). This procedure yielded $\mathrm{CV}=7 \%$ for a filter with a pump, $8 \%$ for filters in passive monitors, and $15 \%$ for ProTek. With the actual set-up of the field tests it is possible that the duplicate samples could have been exposed to slightly different concentrations of sulfur dioxide. The estimated precision is therefore, in our opinion, in good agreement with that of the laboratory tests.

\section{References}

1. Black MS, Herbst RP, Hitchcock DR. Solid adsorbent preconcentration and gas chromatographic analysis of sulfur gases. Anal Chem 50 (1978) 848-851.

2. Coleman SR. A tube diffusion dosimeter for sulfur dioxide. Am Ind Hyg Assoc J 44 (1983) 631-637.

3. Dixon WJ, Massey FJ. Introduction to statistical analysis. Third edition. McGraw Hill, New York, NY 1969, pp 150-192.

4. Fuller EN, Schettler PD, Giddings JC. A new method for prediction of binary gas-phase diffusion coefficients. Ind Eng Chem 58 (1966) 19-27.

5. Kring EV, Henry TJ, Damrell DJ, Bythewood TK. 
Laboratory and field comparison of three methods for monitoring sulfur dioxide in air. Am Ind Hyg Assoc J 44 (1983) 929-936.

6. Kring EV, Lautenberger WJ, Baker WB, Douglas JJ, Hoffman RA. A new passive colorimetric air monitoring badge system for ammonia, sulfur dioxide and nitrogen dioxide. Am Ind Hyg Assoc J 42 (1981) $373-381$.

7. Lautenberger WJ, Kring EV, Morello JA. A new personal badge monitor for organic vapors. Am Ind Hyg Assoc J 41 (1980) 737-746.

8. National Institute for Occupational Safety and Health. Manual of analytical methods. Volume I (P \& C AM 160). US Department of Health Education and Welfare, Cincinnati, OH 1977. (DHEW (NIOSH) publ no $77-157 \mathrm{~A})$.

9. National Institute for Occupational Safety and Health. Manual of analytical methods. Volume 1 (P \& C AM 204). US Department of Health Education and Welfare, Cincinnati, OH 1977. (DHEW(NIOSH) publ no 77-157A).

10. National Institute for Occupational Safety and Health. Manual of analytical methods. Volume 4 (P \& C AM S308). US Department of Health Education and Welfare, Cincinnati, OH 1978. (DHEW NIOSH) publ no $78-175)$.

11. National Institute for Occupational Safety and Health. Manual of analytical methods. Volume 5 (P \& C AM 268). US Department of Health Education and Welfare, Cincinnati, OH 1979. (DHEW (NIOSH) publ no 79-141).

12. Rudling J, Hallberg BO, Hultengren M, Hultman A.
Development and evaluation of field methods for ammonia in air. Scand J Work Environ Health 10 (1984) 197-202.

13. Sawicki E, Mulik JD, Wittgenstein E. Ion chromatographic analysis of environmental pollutants. Ann Arbor Science Publishers, Ann Arbor, MI 1978.

14. Skare I. Bestämning av svaveldioxid i luft. Arbetsmedicinska Institutet, Stockholm 1970. (AI-rapport nr 15).

15. Smith DL, Kim WS, Kupel RE. Determination of sulfur dioxide by adsorption on a solid sorbent followed by ion chromatographic analysis. Am Ind Hyg Assoc J 41 (1980) $485-488$.

16. Snedecor GW, Cochran WG. Statistical methods. Seventh edition. Iowa State University Press, Ames, IA 1980 , pp 291-292.

17. Tompkins FC, Goldsmith RL. A new personal dosimeter for the monitoring of environmental pollutants. Am Ind Hyg Assoc J 38 (1977) 371-377.

18. Vinjamoori DV, Ling CS. Personal monitoring method for nitrogen dioxide and sulfur dioxide with solid sorbent and ion chromatographic determination. Anal Chem 53 (1981) 1689-1691.

19. Volberg NS, Sharikova OP. The use of sorption tubes to sample air for sulfur dioxide determinations. Environmental Protection Agency, Research Triangle Park, NC 1975. (EPA TR76-279).

Received for publication: 9 June 1984 